\title{
A COMPARISON OF CHOLINESTERASE DISTRIBUTION IN THE CEREBELLUM OF SEVERAL SPECIES *
}

\author{
Reinhard L. Friede and LaDona M. Fleming \\ Mental Health Research Institute and Department of Pathology, \\ University of Michigan, Ann Arbor, Michigan
}

(Received 5 June 1963)

Previous efforts in this laboratory have been directed toward systematic mappings of oxidative enzyme activity in the brain. A comparison of the distribution patterns of enzymes involved in glycolysis, citric acid cycle, and hexose-monophosphate shunt revealed almost monotonous similarity both among enzymes and among species; differences were subtle and observed only upon careful scrutiny (FriEDE, FLEMING and KNOLLER, 1963).

In contrast, the present article reports on an almost bewildering species variability in the distribution of acetylcholinesterase (AChE) $\dagger$ and non-specific cholinesterase $(\mathrm{ChE}) \dagger$ in the cerebellum. The discussion of these observations lead to some basic conclusions regarding central synaptic organization. Also, these findings demonstrate the fundamental importance of complete systematic mappings for a just study of the complex chemical architecture of the brain.

\section{MATERIAL AND METHODS}

The following species were used in this study: human, squirrel monkey, cat, cow, rabbit, rat, squirrel, hamster, mouse, pigeon, canary, and parakeet. At least four brains of each species were studied with the exception of monkey and canary, which two brains were available for each. The human material was from normal brains obtained between 5 and $10 \mathrm{hr}$ after death. The animals were either anaesthesized with sodium pentobarbital, or decapitated, and the brains immediately removed. The procedure was as follows: 1) Blocks 2-3 mm thick were fixed in $10 \%$ neutral formalin at $4^{\circ}$ for 3-4 hr. 2) $30 \mu$ frozen sections were placed back into formalin for $30 \mathrm{~min}$. 3) Sections were

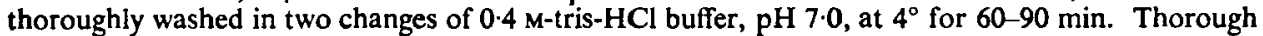
rinsing was important for removing formalin which interferes with the reaction (HOLMSTEDT, 1957). 4) The inhibitor control sections were treated at room temperature for $30 \mathrm{~min}$ in $10^{-6} \mathrm{M}$ inhibitor solution in $0.4 \mathrm{M}$-tris- $\mathrm{HCl}$ buffer, $\mathrm{pH} 7 \cdot 0$.

The inhibitors used were eserine sulphate,$+ \mathrm{BW} \dagger$, and DFP $\dagger$. Immediately before use, the $10^{-8} \mathrm{M}$ solutions were prepared from $10^{-1} \mathrm{M}$ stock solutions. Eserine and BW stock solutions were aqueous and stored at $4^{\circ}$; DFP stock solution was in anhydrous propylene glycol, stored in a desiccator at room temperature. Inhibitor studies were done only for $\mathrm{AChE}$, and the sections were transferred directly from the inhibitor solution to acetylthiocholine iodide incubation medium containing $10^{-6} \mathrm{M}$ of the inhibitor.

5) The composition of the incubation media based on the Gerebtzoff (1959) method was: $0.2 \mathrm{M}$-tris-maleate buffer, $\mathrm{pH} 6.6,44.0 \mathrm{ml} ; 3.75 \%$ glycine, $1.0 \mathrm{ml} ; 0.1$ M-cupric acetate, $1.0 \mathrm{ml}$; acetyl or butyryl thiocholine iodide, $4.0 \mathrm{ml}$. All solutions were made up in glass distilled water; the

\footnotetext{
- This investigation was supported by U.S. Public Health Grant No. B-3250.

$\dagger$ Abbreviations used: AChE, acetylcholinesterase or specific cholinesterase, true cholinesterase, 'e' type cholinesterase, acetocholinesterase, cholinesterase I; ChE, non-specific cholinesterase or pseudocholinesterase, ' $\mathrm{s}$ ' type, unspecified cholinesterases, butyro- and propionocholinesterase, cholinesterase II; BW, [1-5-bis(4-allyldimethylammonium-phenyl)-pentan-3-1-dibromide] (courtesy of John J. Burns, Associate Research Director, Burroughs Wellcome, Tuckahoe, New York); DFP, diisopropylfluorophosphate (Aldrich Chemical Company, Milwaukee, Wisconsin).

$\ddagger$ Mallinkrodt.
} 
first three were prepared in advance and stored at $4^{\circ}$. The substrates were prepared immediately before use in the following amounts: acetylthiocholine iodide, $60 \mathrm{mg}$; or butyrylthiocholine iodide, $74 \mathrm{mg}$; glass distilled $\mathrm{H}_{2} \mathrm{O}, 3.12 \mathrm{ml}$; copper acetate $0.1 \mathrm{M}, 1.04 \mathrm{ml}$. The solution was centrifuged 10-15 min at $3500-4000 \mathrm{rpm}$. Preliminary studies were done on rat brain with both GereBtzOFF (1959) and Koelle (1954) methods and with the final $\mathrm{pH}$ of the media ranging from 5.0 to 7.6 , varied at $\mathbf{0 . 2}$ increments. In general, a good reaction was obtained with both methods between $\mathrm{pH} 6 \cdot 0$ and 7.6. At $\mathrm{pH} 5 \cdot 0$, there was very little reaction and it was still weak at $\mathrm{pH} 5 \cdot 6$, becoming more intense with increase in $\mathrm{pH}$. A final $\mathrm{pH}$ of 6.4 was always used in this study because it gave optimal results. The Koelle and Gerebizoff methods gave essentially the same results except that the Kofi.le method resulted in a reaction in the blood vessels of the molecular layer, while the GEREBTzOFF method did not.

6) lncubation time was $2 \mathrm{hr}$ for $\mathrm{AChE}$ and $16-18 \mathrm{hr}$ for $\mathrm{ChE}$ in $125 \mathrm{ml}$ or larger Erlenmeyer flasks with constant agitation in an Ebcrbach shaker water-bath at $38^{\circ}$. We are in the process of developing a quantitative method for measuring the histochemical reaction of $\mathrm{AChE}$ and have found that constant agitation during incubation is essential for prevention of artifacts due to folding of sections etc; also, agitation increases the rate of the reaction. The shape of Frlenmeyer flasks is best suited for allowing a continuous swirling of the medium which is gentle enough to prevent section damage. After incubation, the entire contents of the flask (10-40 sections) were gently poured into a stainless steel cup-like strainer with a handle. The incubation medium was drained off, and the carrier with sections was gently, but rapidly, plunged up and down in a 2-1. beaker filled with glass-distilled water for $30 \mathrm{sec}$, in light yellow ammonium sulphide solution for $15 \mathrm{sec}$, and in three changes of glassdistilled water $10-15 \mathrm{sec}$ each. The sections were stored in $10 \%$ neutral formalin until mounted in glycerin gel or permount. Some sections from each specimen were counterstained with chromalum gallocyanin.

The histochemical methods for NAD-diaphorase and lactate dehydrogenase have been described in earlier publications.

\section{RESULTS}

\section{A. Species consistency of $A C h E$ pattern in two reference regions}

For cach brain, some sections of putamen (or N. caudatus) and some sections which included nucleus dentatus or nucleus fastigii were always incubated with the other cerebellar sections in the same flask of incubation medium. The reaction in the putamen and the cerebellar nuclei served as a baseline for comparison with that in the cercbellar cortex of the same specimen.

In all species studied, the reaction for AChE in the putamen was very intense, exceeding that in most other nuclei of the brain. Likewise, little, if any, species difference could be seen in the cerebellar nuclei. The reaction in the nucleus dentatus was weak in comparison with that in putamen or cerebellar cortex and it only slightly exceeded that in the surrounding white matter. The only observation suggesting a species difference in the dentate $\mathrm{N}$. was the variable presence or absence of a diffuse enzyme reaction in the cytoplasm of the nerve cells. In all the species, the white matter showed a weak reaction, mostly localized in axons.

\section{B. Distribution of acetylcholinesterase in cerebellar cortex}

The distribution of cholinesterase (AChE) in the layers of the cerebellar cortex varied considerably among species; however, no variations were ever observed within a given species. Among the twelve species studied, five types of distribution of enzyme activity could be distinguished in the molecular and granular layers of the cortex: 1) Strong enzyme reaction in the molecular layer and little in the granular layer (Fig. 2), 2) strong reaction in the granular layer and little in the molecular layer (Fig. 3), 3) weak reaction in both layers (Fig. 1), 4) strong reaction in both layers (Fig. 4), and 5) markedly variable intensity of the reaction among folia (Fig. 5) (some folia were like type 2, strong in the granular layer and weak in the molecular layer, whereas other folia had a weak reaction in both layers like Type III. The enzyme 


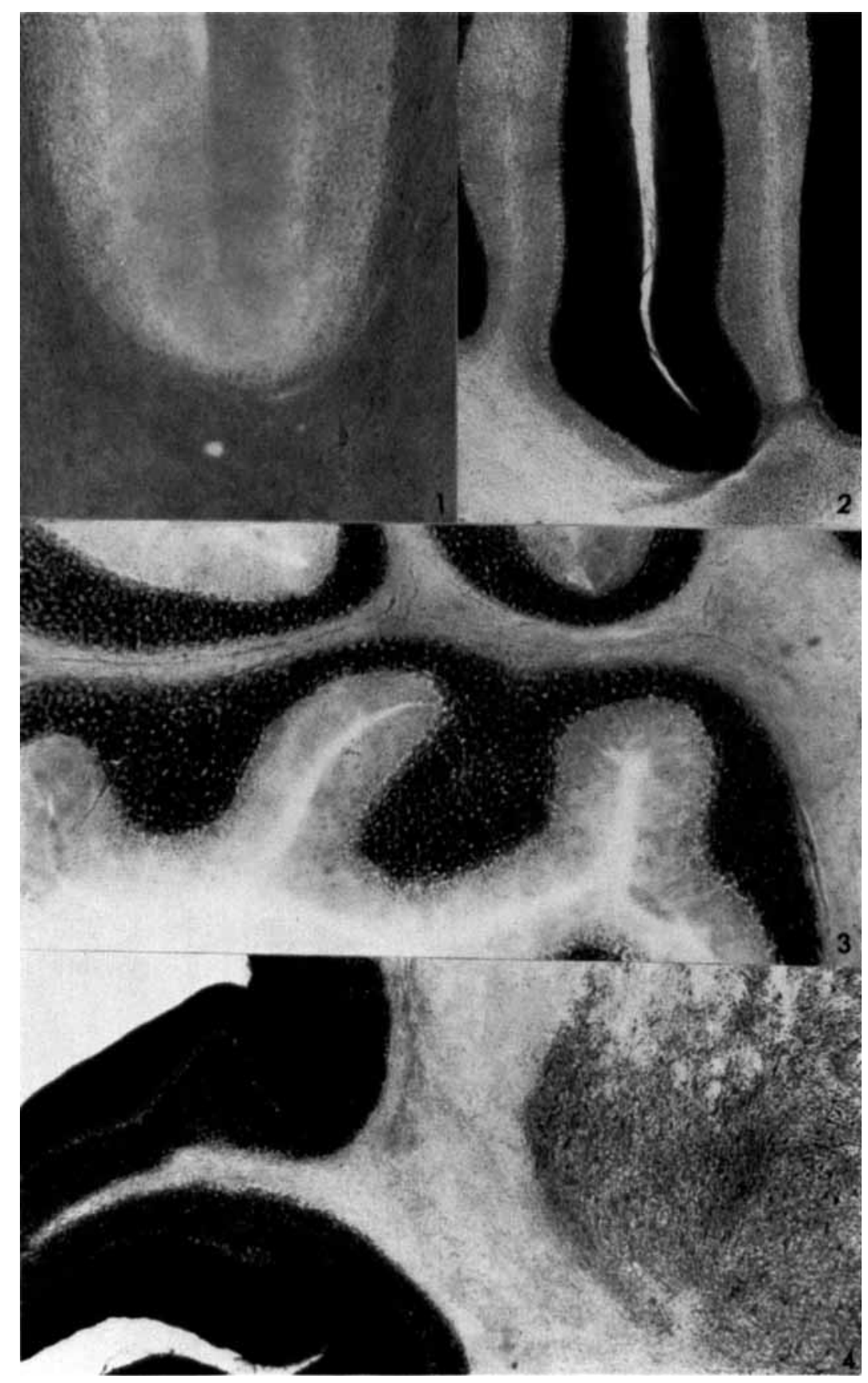

Fics. 1-4 -Acetylcholinesterase (AChE)

1. Squirrel monkey; absence of AChE in both cortical layers; 2. Parakeet; Strong $\mathrm{AChE}$ in the molecular layer, little reaction in the granular layer; 3. Cat: strong AChE in the granular layer only: 4. Squirrel; strong AChE in both layers; a segment of the . . dentatus (right half of the picture) is included for comparison. 


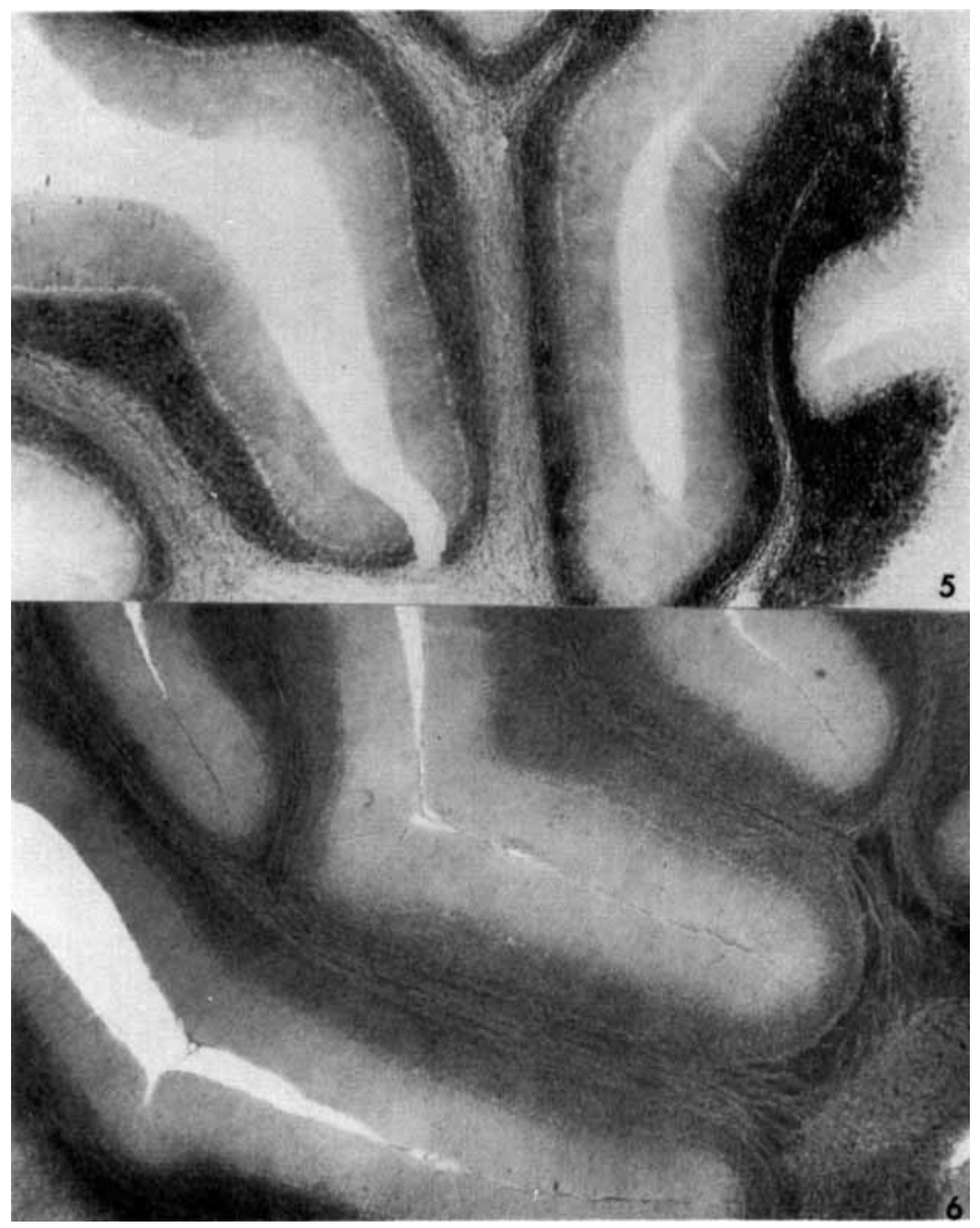

FIGS. S and 6-Acetylcholinesterase

5. Rat: marked variation of AChE among folia of the vermis; 6. Hamster: very little $A C h E$ in both cortical layers. 
reaction in the layer of Purkinje cells was consistent, showing enzyme activity at the membrane of the cells as is seen in the dentate nucleus. The intensity of the reaction in the cytoplasm of Purkinje cells and their proximal dendrites varied somewhat among species; it was particularly strong in the cow.

Type I: Strong enzyme reaction in the molecular layer: This pattern was characteristic for all avian species investigated (pigeon, canary, parakeet). A very strong reaction for $\mathrm{AChE}$ was distributed throughout the neuropil of the molecular layer, usually somewhat stronger in the deeper than the superficial part (Fig. 2). Besides the homogeneous diffuse staining, there was some reaction in glial cells and capillary walls. The reaction in the granular layer was contrastingly weak and only slightly stronger than that in the white matter (Fig. 2); cytological localization was not possible in this layer.

A similar pattern of $\mathrm{AChE}$, though weaker in the molecular layer, was also found in the human cerebellum; however, the avian group enzyme differed from human by its response to inhibitors (see bclow).

Type II: Strong enzyme reaction in the granular layer: This pattern, inverse to Type I, was characteristic for cat. The molecular layer stained only slightly darker than the white matter. The granular layer, in contrast, had an extremely intense reaction, most of which appeared to be localized in the synaptic ccrebellar glomeruli (Fig. 3). There were no definite variations among folia.

Type III: Weak enzyme reaction in both layers: This pattern was observed in the squirrel monkey (Cebus cebus). There was no reaction in either layer and, in fact, the layers appeared lighter than the adjacent white matter (Fig. 1). The absence of a reaction was not an artifact, as both dentate nucleus and putamen, incubated in the same container, showed a reaction comparable in intensity to that of other species.

Likewise, the golden hamster (Mesocricetus aurathus) had very little enzyme in either layer, but there was a slight reaction; the granular layer had slightly more reaction than the white matter (Fig. 6).

Type IV: Strong enzyme reaction in both layers: A nearly equal enzyme reaction was observed in both cortical layers of the squirrel (Sciurus ruber); this strong reaction in the cortex was in marked contrast to that of the dentate nucleus (Fig. 4) which showed its normal weak staining. There was a strong reaction in both cortical layers in guinea pig, although it was not quite as intense as, and was more variable than, that seen in squirrel.

Type V: Marked variation of the enzyme reaction among cerebellar folia: In rat, mouse, rabbit, and cow, the reaction in the molecular layer was consistently weak, but there were striking differences of enzyme distribution in the granular layer of different folia. There was a very strong reaction in the granular layer of some folia of the vermis, but in many other folia, the reaction in granular layer was weak, only slightly exceeding that in the molecular layer (Fig. 5). Some folia showed a transitional pattern with patchy cell groupings of strong activity and intervening areas of weak activity in the granular layer. In rat, rabbit, and mouse, there were many more folia with a weak reaction than with a strong one, whereas in cow, the folia with a strong reaction outnumbered those with a weak reaction. A similar pattern of some folia with a strong reaction seemed to extend into the hemispheres, but the exact topography cannot be given in the absence of serial reconstructions. The reaction in Purkinje cell perikarya did not change with the variations of the granular layer. 


\section{Inhibitors}

Eserine $\left(10^{-5} \mathrm{M}\right)$ completely inhibited the reaction for $\mathrm{AChE}$ in all species. $\mathrm{BW}\left(10^{-5} \mathrm{M}\right)$ inhibited the reaction for $\mathrm{AChE}$ in all mammalian species, but not in birds. DFP $\left(10^{-5} \mathrm{M}\right)$ inhibited $\mathrm{AChE}$ in all of the species studied except the cat; however, the inhibition was only partial in rat, guinea pig, and squirrel.

\section{Distribution of non-specific cholinesterase (ChE)}

There was some variation among species in the distribution of $\mathrm{ChE}$, but not nearly as much as for AChE. The ChE reaction was stronger in the molecular layer than in the granular layer in pigeon, canary, parakeet, human, monkey, and cow (Fig. 8); the distribution was vice versa in cat, rat, rabbit, guinea pig, mouse, and hamster (Fig. 9). Thus, the patterns of AChE and ChE were similar in some species (e.g., birds), but were inverse in others (e.g., cow, monkey). Cytologically, the ChE was diffuse in the molecular layer except for the staining of numerous straight processes running perpendicular to the surface of the cortex (Fig. 8). The straight course and the scarcity of branchings suggested that these were glial cell processes rather than dendrites of Purkinje cells. ChE could be demonstrated unequivocally in the perikarya of Bergmann glial cells of monkey and cow if the nuclei were counterstained with chromalum gallocyanin. In pigeon, parakeet and rabbit, ChE was clearly demonstrated in the perikarya of Purkinje cells, while in the cow, there was a reaction in some Purkinje cell perikarya, but not in others. Thus, the opinion that $\mathrm{ChE}$ is localized only in glia and AChE only in neurons should not be accepted as a general rule. The pattern in squirrel was exceptional, ChE being extremely strong in the superficial portion of the molecular layer (Fig. 7). Another exception to most of the patterns for $\mathrm{ChE}$ was observed in human cerebellum, where the reaction was extremely strong in the deep portion of the molecular layer.

In the granular layer of cat, rat, rabbit, guinea pig, mouse, and hamster, there was a diffuse distribution of $\mathrm{ChE}$, sometimes with an indistinct flocculated or mottled pattern. A marked reaction in blood vessels was seen in canary and rat. In white matter, the reaction for ChE was always comparatively stronger than that of $\mathrm{AChE}$; ChE was localized both in perikarya of glial cells and in axons. In many species (parakcet, mouse, guinea pig, cat, monkey), the glia cells in the subcortical portions of white matter had a markedly stronger reaction than those in the deeper parts of white matter (Fig. 10). Even where the distributions of $\mathrm{AChE}$ and $\mathrm{ChE}$ were similar (e.g., in birds) there were always sufficient differences of cytological localization to distinguish the patterns from each other. This, and the marked difference in incubation times, led us to believe that there was very little, if any, overlap of substrate specificity in these methods.

The patterns of AChE and ChE gave nearly every species a 'code' by which it could be identified like a fingerprint (Table 1).

\section{E. Distribution of oxidative enzymes}

In contrast to the varied patterns of cholinesterases, there were no species differences in the distribution of oxidative enzymes (NAD-diaphorase, lactate dehydrogenase) which were always demonstrated in scctions cut from the same blocks used for the cholinesterase study. 


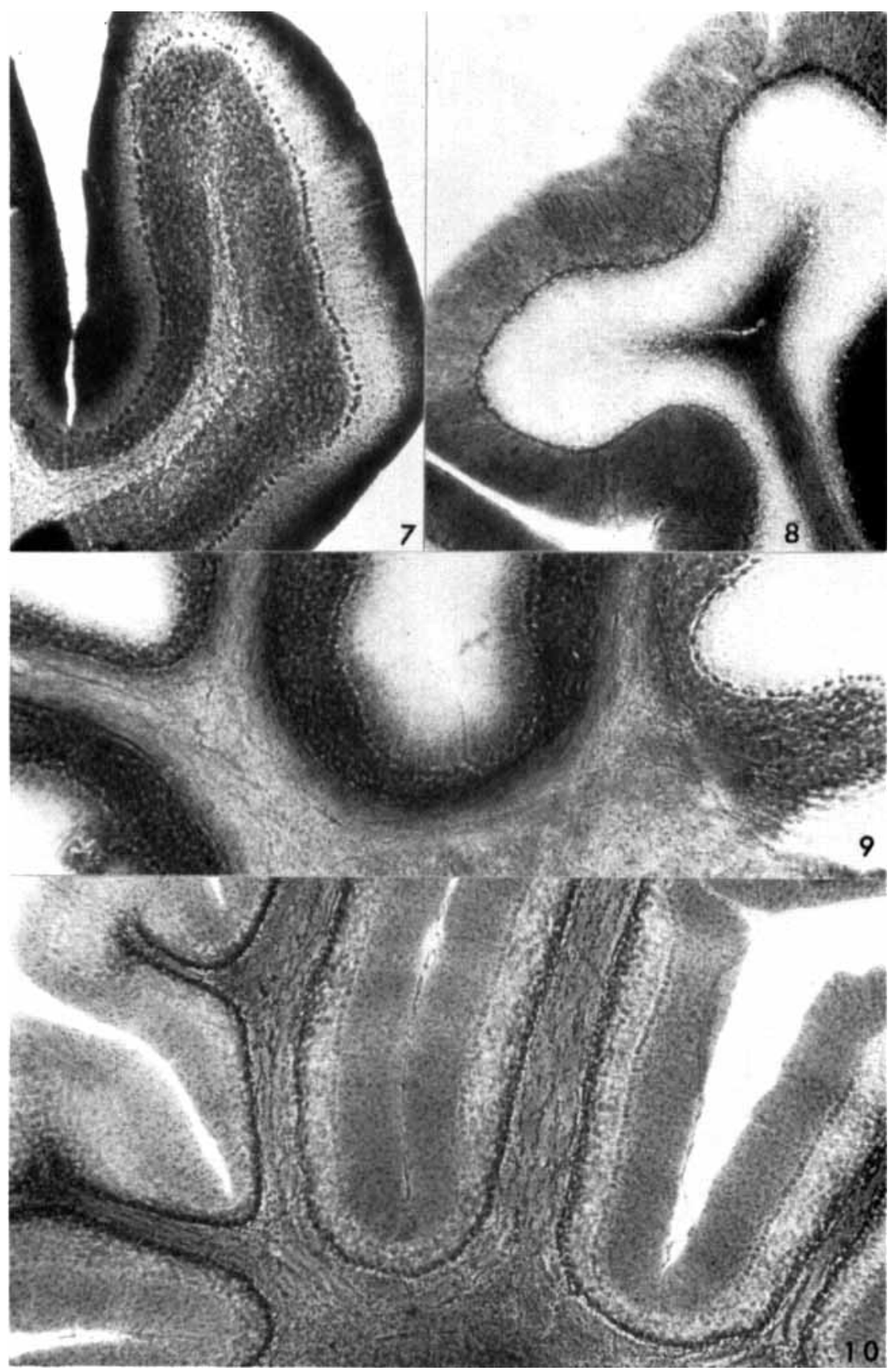

FIGs. 7 -10 -...Non-specific cholinesterase (ChE)

7. Squirrel; extremely strong ChE in the superficial portion of the molecular layer; 8. Squirrel monkey; medium reaction for ChF in the molecular layer. Note the reaction in the numerous cell processes running perpendicular to the cortical surface; 9. Rabbit; marked ChF in the granular layer: 10. Squirrel; strong reaction for $\mathrm{ChE}$ in the glia cells in the subcortical zone of white matter. 


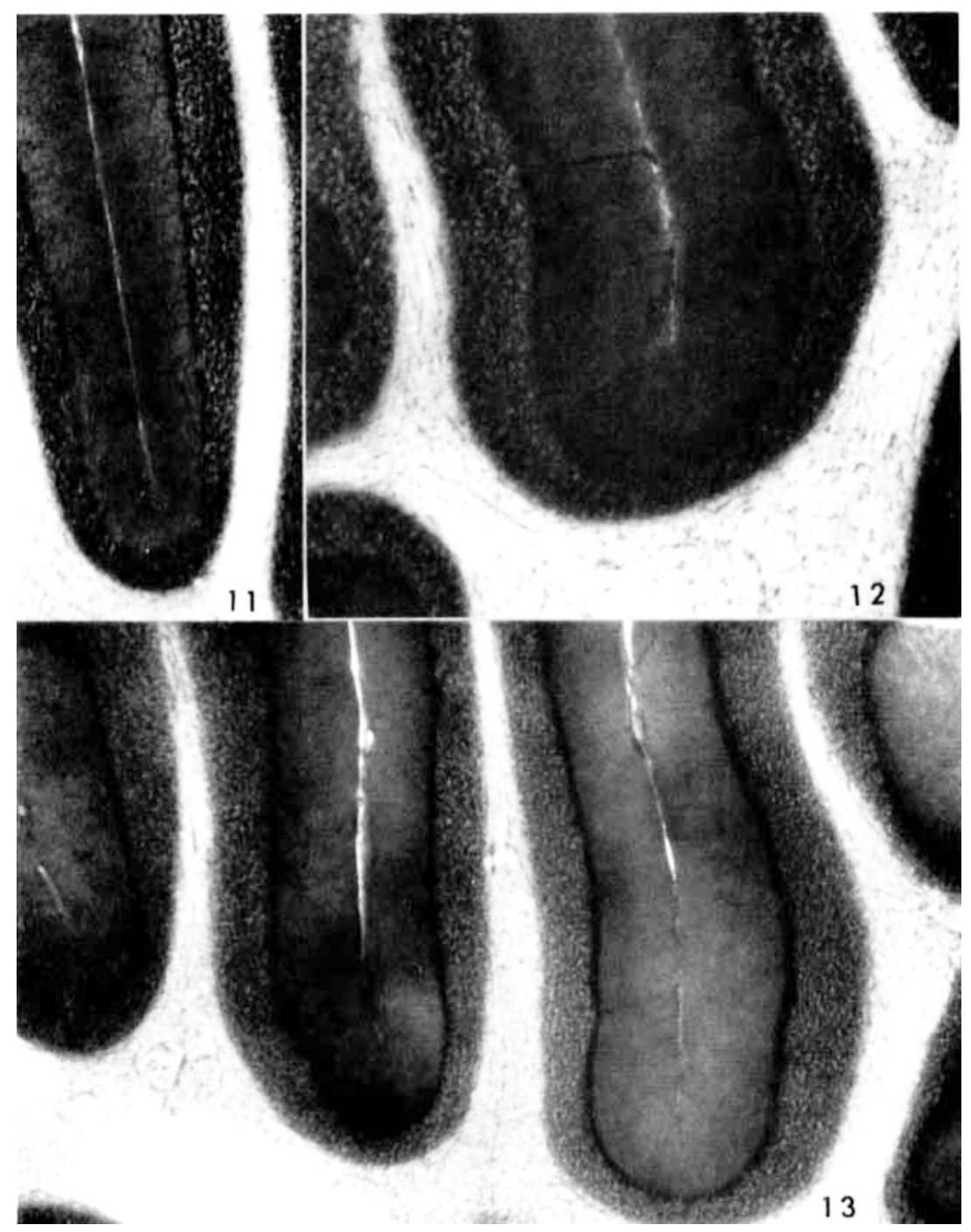

Ficis. 11 13 -Nearly identical patterns of NAD-diaphorase in squirrel monkey (11), rabbit (12) and canary (13). 
Oxidative enzymes always showed a strong reaction diffusely distributed in the molecular layer; the large proximal portions of the Purkinje dendrites were distinguishable with a more intense reaction. Also, there was a strong reaction in the perikarya of the Purkinje cells and in the synaptic glomeruli of the granular layer (Figs. 11-13). Little reaction was seen in Bergmann's glia cells and the clusters of granule cells. These patterns have been described in detail elsewhere (FRIEDE and Fleming, 1962; FRIEDE, 1963).

TABLE 1

\begin{tabular}{|c|c|c|c|c|c|c|c|}
\hline & \multicolumn{4}{|c|}{ Acetylcholinesterase } & & \multicolumn{2}{|c|}{ Non-specific cholinesterase } \\
\hline & \multirow{2}{*}{$\begin{array}{l}\text { molecular } \\
\text { layer }\end{array}$} & \multirow{2}{*}{$\begin{array}{l}\text { granular } \\
\text { layer }\end{array}$} & \multirow[b]{2}{*}{ Eserine } & \multicolumn{2}{|l|}{ Inhibitors } & \multirow{2}{*}{$\begin{array}{l}\text { molecular } \\
\text { layer }\end{array}$} & \multirow{2}{*}{$\begin{array}{l}\text { granular } \\
\text { layer }\end{array}$} \\
\hline & & & & DFP & BW & & \\
\hline Man & + & 0 & complete & complete & complete & $\begin{array}{l}\text { extremely strong } \\
\text { in inner portion }\end{array}$ & $\mathrm{O}$ \\
\hline Monkey & 0 & 0 & complete & complete & complete & + & 0 \\
\hline $\begin{array}{l}\text { Cat } \\
\text { Cow }\end{array}$ & $\mathrm{O}$ & $+r+t$ & complete & none & complete & 0 & + \\
\hline most folia & 0 & + & complete & complete & complete & $T$ & 0 \\
\hline some folia & 0 & 0 & complete & complete & complete & + & 0 \\
\hline Rabbit & & & & & & & \\
\hline $\begin{array}{l}\text { most folia } \\
\text { some folia }\end{array}$ & $\stackrel{0}{0}$ & $\begin{array}{c}0 \\
++\end{array}$ & $\begin{array}{l}\text { complete } \\
\text { complete }\end{array}$ & $\begin{array}{l}\text { complete } \\
\text { complete }\end{array}$ & $\begin{array}{l}\text { complete } \\
\text { complete }\end{array}$ & $\begin{array}{l}0 \\
0\end{array}$ & $\begin{array}{l}+ \\
+\end{array}$ \\
\hline Rat & & & & & & & \\
\hline most folia & 0 & 0 & complete & partial & complete & 0 & $t$ \\
\hline a few folia & 0 & ++ & complete & partial & complete & 0 & + \\
\hline Squirrel & ++ & ++ & complete & partial & complete & $\begin{array}{l}\text { extremely strong } \\
\text { in outer portion }\end{array}$ & 0 \\
\hline $\begin{array}{l}\text { Guinea pig } \\
\text { Hamster } \\
\text { Mouse }\end{array}$ & $\begin{array}{c}++1 \\
0\end{array}$ & $0^{+1}$ & $\begin{array}{l}\text { complete } \\
\text { complete }\end{array}$ & $\begin{array}{c}\text { partial } \\
\text { complete }\end{array}$ & $\begin{array}{l}\text { complete } \\
\text { complete }\end{array}$ & $\begin{array}{l}0 \\
0\end{array}$ & $\begin{array}{l}t \\
t\end{array}$ \\
\hline most folia & 0 & 0 & complete & complete & complete & 0 & + \\
\hline some folia & 0 & ++ & complete & complete & complete & 0 & 0 \\
\hline Pigeon & ++ & 0 & complete & complete & none & $\div$ & 0 \\
\hline Canary & ++ & 0 & complete & complete & none & $\rightarrow$ & 0 \\
\hline Parakeet & $T+$ & 0 & complete & complete & none & $i$ & 0 \\
\hline
\end{tabular}

\footnotetext{
O little or no reaction

+ medium reaction

++ strong reaction
}

\section{DISCUSSION}

The observations described in this article are in good agreement with many previous reports on the distribution of $\mathrm{AChE}$ and $\mathrm{ChE}$ in the cerebellum of individual species; however, a systematic comparison of these enzymes in the cerebellum of twelve species revealed an amazing species variation which has not received much emphasis hitherto. Our data agree with the following previous reports: A strong reaction for cholinesterase in the molecular layer of the pigeon (SINDEN and SCHARRER, 1949, Fig. 2); the same distribution described by Capuro, Zaccheo, and Viale (1960) and CavanaGH and Holland (1961) in several avian species (both groups of investigators did comment on the difference between this pattern and what was considered by them to be the 'mammalian' pattern); DE GIACOMO's (1962, Fig. 6) 
findings in man; SNELL's (1961, Fig. 16) description in cat; varied findings reported in rodents by Koelle (1954), Gerebtzoff (1959), Tewari and Bourne (1962) and Csillik, Joo and KaSA (1963). The last-named authors were the first to comment on the regional variation of the reaction among folia; they found, as we did, AChE in the granular layer of the nodule, lower uvula, and flocculi, while the hemispheres were negative (their Fig. 1 is nearly identical with our Fig. 5). RoBins and Smith (1953) commented that there was no significant difference between vermis and hemispheres in Macaca mulatta, and this is consistent with the histochemical observations in other species.

Species differences in the histochemical localization of $\mathrm{AChE}$ and $\mathrm{ChE}$ have been reported by Brightman and Albers (1959). Our comparison of species patterns of $\mathrm{AChE}$ and $\mathrm{ChE}$ in the cerebellar cortex, cerebellar nuclei, and putamen demonstrated that there is more species variation of the enzyme patterns in some parts of the brain than in others. This variation of $\mathrm{AChE}$ was in contrast with the consistency of the distribution of several oxidative enzymes, both among cach other and among species. BENNETT et al. (1958) likewise found significant differences of AChE among two strains of rats, but none for lactate dehydrogenase. Careful systematic mappings which document species variability as well as regional differences within a species would provide an invaluable baseline for comparative pharmacology.

FELDBERG and Vocit (1948) theorized that "some, at least, of the motor and sensory pathways, consist of chains of neurons which are alternately cholinergic and non-cholinergic in character." KolLLE (1955) suggested that "the terms cholinergic and adrenergic may refer to the predominant, but not necessarily the exclusive, transmitting agents of the respective nerve fibres." The inverse distribution of $\mathrm{AChE}$ in the cerebellar layers of cat and bird would seem to be in agreement with this concept (POPE, 1957). However, histochemical findings in the retina and the superior colliculus might indicate that two consecutive neurons in a pathway could be cholinergic (Hess, 1960). TORACK and BARRNETT (1962), combining electron microscopy with histochemistry, demonstrated AChE in some synapses, but not in others. DF. ROBERTIS (1961 \& 1962) concluded from subcellular fractionation that there are more noncholinergic than cholinergic endings in the brain.

FELDBERG and VOGT's (1948) theory of chains of cholinergic and non-cholinergic neurons is essentially supported by our findings; however, our data strongly suggest that these neurons are not necessarily in alternate sequence. In fact, the type of transmission seems to be rather haphazard, at least in the cerebellum, where every conceivable type of combination was found. The cerebellar cortex enables one to study two subsequent synaptic regions in the same section; that is, the synapses between the afferent mossy fibres and the granule cells (cerebellar glomeruli) and the synapses between the granule cells and Purkinje cells (molecular layer). The anatomical architecture of these circuits, as well as their physiological significance, probably represents one of the most stable 'blueprints' of the brain throughout phylogenetic development. Oxidative enzyme patterns indicate that the energy metabolism in these regions is remarkably consistent among species. Cerebellar afferents and efferents are subject to some differences among species (KAPPERS, HuBER and CrosBY, 1960), but there are no differences that would be sufficiently dramatic to explain the extremely different AChE patterns; e.g., even among the rodents. Also, there is no reason to believe that the total synaptic activity in either granular or 
molecular layer would be significantly different among species. The same reasoning applies to any possible difference of inhibitory or facilitatory mechanisms in the cerebellum. From all these considerations the most logical interpretation of our findings seems to be that there is, in the cerebellum, a possible choice between a cholincrgic or non-cholinergic type of transmission, and that either type of transmission can be used by a given species to operate the same circuit. Of course, the biochemical nature of the alternate non-cholinergic type of transmission remains an open question.

\section{SUMMARY}

Histochemical studies of acetylcholinesterase in the cerebellar cortex of twelve species showed five types of enzyme distribution: 1) Little or no enzyme reaction in both layers (monkey, hamster); 2) strong reaction in both layers (squirrel, guinea pig); 3) strong reaction in the molecular layer only (bird, man); 4) strong reaction in the granular layer only (cat); and 5) marked variability among folia (cow, rat, rabbit, mouse). Non-specific cholinesterase also showed some variation among species which was independent of that of acetylcholinesterase. The variability of cholinesterase distribution was in marked contrast to the consistent distribution of oxidative enzymes (NAD diaphorase, lactate dehydrogenase). These findings permit conclusions regarding principles of central synaptic organization.

\section{REFERENCES}

Bennett E. L., Krech D., Rosenzweig M. R., Karlsson H., Dye N. and Ohlander A. (1958) J. Neurochem. 3, 153.

Brightman M. W. and Albers R. W. (1959) J. Neurochem. 4, 244.

Capurro S., Zaccheo D. and Viale G. (1960) C. R. Ass. Anat. 46, 146.

Cavanagh J. B. and Holland P. (1961) Nature (Lond.) 190, 735.

Csillik B., Joo F. and KASA P. (1963) J. Histochem. Cytochem. 11, 113.

DE ROBERTIS E. (1961) Biochem. Pharmacol. 8, 95.

de Robertis E., Pellegrino de Iraldi A., Rodriguez de lores Arnaiz G. and Salganicoff l. (1962) J. Neurochem. 9, 23.

DE GIACOMO P. (1962) Proc. IVth Internat. Congr. Neuropath. Vol. 1, p. 198, Thieme, Stuttgart.

Friede R. L. and Fleming L. M. (1962) J. Neurochem. 9, 179.

Friede R. L., Fleming L. M. and KNOLler M. (1963) J. Neurochem. 10, 263.

FRIEDE R. L. (1963) Arch. Neurol. (Chic.) 8, 67.

Feldberg W. and Vogt M. (1948) J. Physiol. (Lond.) 107, 273.

GerebTzOFF M. A. (1959) Cholinesterases: A histochemical contribution to the solution of some functional problems. Internat. Series of Monographs on Pure and Applied Biology, Vol. 3, Pergamon Press, London.

Hess A. (1960) J. exp. Zool. 144, 11.

HOLMSTEDT B. (1957) Acta physiol. scand. 40, 331.

Kappers Ariens C. U., Huber G. L. and Crosiy E. C. (1960) The comparative anatomy of the nervous system of vertebrates including man, Hafner, New York.

KOELLE G. B. (1954) J. comp. Neurol. 100, 211.

Koelle G. B. (1955) J. Pharmacol. exp. Ther. 114, 167.

POPE A. (1957) In Ultrastructure and cellular chemistry of neural tissue (Edited by WAELSCH H.) p. 212, Hoeber-Harper, New York.

Robins E. and Smith D. E.(1953) Res. Publ. Ass. nerv. ment. Dis. Vol. 32, p. 305, Williams and Wilkins, Baltimore.

Sinden J. and Scilarrer E. (1949) Proc. Soc. exp. Biol. (N.Y.) 72, 60.

SNELL R. S. (1961) Bibl. anat. (Basel) 2, 50.

TeWARI H. B. and Bourne G. H. (1962) Exp. Cell Res. 27, 173.

TORACK R. M. and BARRNetT R. J. (1962) Exp. Neurol. 6, 224. 